\title{
Clinical Analysis and Management of Esophageal Perforation
}

\author{
Haeng Seon Shim ${ }^{1}$, Myung Gu Kim², and Joon Soo Kim ${ }^{3}$ \\ ${ }^{1}$ Departments of Anesthesiology and Pain Medicine, ${ }^{2}$ Otorhinolaryngology-Head and Neck Surgery, ${ }^{3}$ Neurosurgery, \\ Samsung Changwon Hospital, Sungkyunkwan University School of Medicine, Changwon, Korea
}

\section{식도 천공의 치료 및 임상적 분석}

심행선 ${ }^{1} \cdot$ 김명구 $^{2} \cdot$ 김준수 $^{3}$

성균관대학교 의과대학 삼성창원병원 마취통증의학교실, ${ }^{1}$ 이비인후과학교실, ${ }^{2}$ 신경외과학교실 ${ }^{3}$

\author{
Received April 26, 2016 \\ Revised July 24, 2016 \\ Accepted July 27, 2016 \\ Address for correspondence \\ Myung Gu Kim, MD, PhD \\ Department of Otorhinolaryngology- \\ Head and Neck Surgery, \\ Samsung Changwon Hospital, \\ Sungkyunkwan University \\ School of Medicine, \\ 158 Paryong-ro, MasanHoewon-gu, \\ Changwon 51353, Korea \\ Tel $+82-55-290-6067$ \\ Fax $+82-55-290-6578$ \\ E-mail mgent.kim@samsumg.com
}

Background and Objectives Esophageal perforation is relatively uncommon and requires careful diagnostic evaluation and expert management. It has a high mortality due to significant mediastinal and pleural contamination leading to sepsis and multiple organ failure. We reviewed our experience of esophageal perforation to determine how to better recognize such a lesion and facilitate its correct management.

Subjects and Method A retrospective chart review was performed on all patients treated for esophageal perforation from January 2000 to March 2016. These patients have been studied with respect to gender and age distribution, causes, sites, clinical manifestation, complications, management and postoperative complications.

Results Patients ranged in age from 21 to 87 years, with an average age of 57.6 \pm 12.4 years. Fifty of the patients were men and 21 were women. The causes of the perforations were as follows: foreign body retention (18 patients), trauma (17 patients), Boerhaave's syndrome (22 patients), and iatrogenic (14 patients). The sites of esophageal perforation were: the cervical esophagus (25 patients), thoracic esophagus (44 patients) and abdominal esophagus (2 patients). Primary repair only was performed in seven $(9.9 \%)$ patients, whereas $32(45 \%)$ patients were treated with primary repair \& patch, seven $(9.9 \%)$ patients with T-tube drainage. Exclusion \& division were performed in three (4.2\%) patients and esophagectomy was performed in two $(2.8 \%)$ patients. Twenty $(28.2 \%)$ patients were treated conservatively.

Conclusion Early recognition and appropriate management of esophageal perforation are essential for reduction of morbidity and mortality.

Korean J Otorhinolaryngol-Head Neck Surg 2016;59(9):668-71

Key Words Boerhaave's syndrome - Esophageal perforation · Foreign body · Iatrogenic · Trauma.

\section{서 론}

식도 천공은 흔하지는 않지만 임상 증상이 다른 질병과 비 슷한 경우가 적지 않아 진단이 늦어지거나 정확한 치료가 이 루어지지 않을 경우 그 유병률이나 사망률이 급격히 상승하 는 질환이다. ${ }^{1-3)}$ 식도는 장막층이 없고 주위에 느슨한 소성조 직으로 둘러싸여 있는 독특한 구조를 가지고 있어 천공 시
세균과 소화효소가 쉽게 종격동에 도달하여 심한 종격동염 과 농흥, 패혈증을 일으켜 궁극적으로 다발성 장기 부전을 초래한다. 따라서 정확한 진단과 빠른 치료가 매우 중요하다. 식도 천공에 대한 치료방법은 항생제와 수액제의 발달, 외과 적 수술기법의 향상 등으로 성적이 향상되고 있으나, 여전히 높은 사망률을 보이고 있고 환자의 연령 증가, 식도암의 빈도 증가, 내시경조작이나 중재시술의 발달로 인해 의인성 천공 
Esophageal Perforation I Shim HS, et al.

의 빈도가 증가하고 있는 추세이다.

이에 저자들은 2000년 1월부터 2016년 3월까지 식도 천공 환자 71 명을 대상으로 임상적 분석을 통하여, 향후 진단과 치 료에 도움을 얻고자 하였다.

\section{대상 및 방법}

2000년 1월부터 2016년 3월까지 식도 천공 환자 71명을 대 상으로 성별과 연령분포, 천공의 원인, 천공의 위치, 천공의 임 상 양상, 천공 후 합병증, 치료방법과 수술 후 합병증을 비교 분석하였다.

\section{결 과}

성별은 남자에서 월등하게 많이 분포하였는데, 남자가 50명 (70.4\%)인 반면에 여자는 21명(29.6\%)이었다(Table 1). 발생 연령은 평균 $57.6 \pm 12.4$ 세였고 연령분포는 10대 이하가 0명 $(0 \%), 20$ 대가 1 명 $(1.4 \%), 30$ 대가 2명(2.8\%), 40대가 8명 $(11.3 \%), 50$ 대가 17 명(23.9\%), 60대가 17 명(23.9\%), 70대가 18 명(25.4\%), 80대 이상이 8명(11.3\%)이었다(Table 1).

식도 천공의 원인은 Boerhaave's 증후군이 22명(31.0\%), 이 물질이 18 명(25.4\%), 외상성이 17 명(23.9\%), 의인성이 14 명 $(19.7 \%)$ 이었다(Table 1). 식도 천공의 위치는 경부가 25명 (35.2\%), 흥부가 44명(62.0\%), 복부가 2명(2.8\%)이었다(Table 1).

식도 천공의 임상 양상은 흥부나 경부 통증 46명(64.8\%), 호 흡곤란 18명(25.4\%), 구토 16명(22.5\%), 토혈 14명(19.7\%), 발열 12 명(16.9\%), 연하곤란 12명(16.9\%), 피하기종 16명(22.5\%), 기흥 5명(7\%), 종격동기종 5명(7\%)이었다(Table 1).

식도 천공 후 합병증으로 농흥이나 늑막 삼출이 29명(40.8\%), 종격동염이 6명(8.5\%), 패혈증이 2명(2.8\%), 폐농양이 2명(2.8\%), 복막염이 2명(2.8\%)이었다(Table 1).

식도 천공 환자 총 71 명 중 20명(28.2\%)은 보존적 치료를 하 였고, 단순 일차적 봉합술은 7명(9.9\%) 환자에게 시행하였고, 보강조직을 사용한 경우가 32명(45\%)이었고, T-tube 배액술 을 시행한 환자는 7명(9.9\%)이었고, 배제술과 전환술을 시행 한 환자는 3 명(4.2\%)이었고, 식도 제거술을 한 환자는 2 명 $(2.8 \%)$ 이었다(Table 1$)$.

식도 천공 수술 후 합병증은 누출 8예(10\%), 패혈증 4예 (5.6\%), 상처 감염 3예(4.2\%), 폐렴 4예(5.6\%), 출혈 4예(5.6\%), 급성 신부전 3예(4.2\%)였다(Table 1).
Table 1. Characteristics of patients with esophageal perforation

\begin{tabular}{|c|c|c|}
\hline & Number & Percentage \\
\hline Enrolled patients & 71 & 100 \\
\hline Gender (M/F) & $50 / 21$ & $70.4 / 29.6$ \\
\hline \multicolumn{3}{|l|}{ Age } \\
\hline Under 20 & 0 & 0 \\
\hline $20-29$ & 1 & 1.4 \\
\hline $30-39$ & 2 & 2.8 \\
\hline $40-49$ & 8 & 11.3 \\
\hline $50-59$ & 17 & 23.9 \\
\hline $60-69$ & 17 & 23.9 \\
\hline $70-79$ & 18 & 25.4 \\
\hline Above 80 & 8 & 11.3 \\
\hline \multicolumn{3}{|l|}{ Perforation site } \\
\hline Cervical & 25 & 35.2 \\
\hline Thoracic & 44 & 62 \\
\hline Abdominal & 2 & 2.8 \\
\hline \multicolumn{3}{|l|}{ Causes of perforation } \\
\hline Boerhaave's syndrome & 22 & 31 \\
\hline latrogenic & 14 & 19.7 \\
\hline Trauma & 17 & 23.9 \\
\hline Foreign body & 18 & 25.4 \\
\hline \multicolumn{3}{|l|}{ Clinical manifestation } \\
\hline Chest/neck pain & 46 & 64.8 \\
\hline Dyspnea & 18 & 25.4 \\
\hline Vomiting & 16 & 22.5 \\
\hline Hematemesis & 14 & 19.7 \\
\hline Fever & 12 & 16.9 \\
\hline Subcutaneous emphysema & 16 & 22.5 \\
\hline Dysphagia & 12 & 16.9 \\
\hline Pneumothorax & 5 & 7 \\
\hline Pneumomediastinum & 5 & 7 \\
\hline \multicolumn{3}{|l|}{ Complications } \\
\hline Empyema/pleural effusion & 29 & 40.8 \\
\hline Mediastinitis & 6 & 8.5 \\
\hline Sepsis & 2 & 2.8 \\
\hline Lung abscess & 2 & 2.8 \\
\hline Peritonitis & 2 & 2.8 \\
\hline \multicolumn{3}{|l|}{ Treatment } \\
\hline Conservative treatment & 20 & 28.2 \\
\hline Primary repair only & 7 & 9.9 \\
\hline Primary repair \& patch & 32 & 45 \\
\hline T-tube drainage & 7 & 9.9 \\
\hline Exclusion \& division & 3 & 4.2 \\
\hline Esophagectomy & 2 & 2.8 \\
\hline \multicolumn{3}{|l|}{ Postoperative complications } \\
\hline Leakage & 8 & 10 \\
\hline Sepsis & 4 & 5.6 \\
\hline Wound infection & 3 & 4.2 \\
\hline Pneumonia & 4 & 5.6 \\
\hline Bleeding & 4 & 5.6 \\
\hline Acute renal failure & 3 & 4.2 \\
\hline
\end{tabular}




\section{고 찰}

식도 천공은 근대 의학발전과 더불어 치료 성적의 향상이

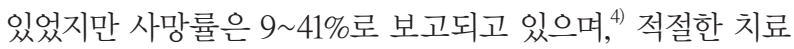
가 이뤄지지 않은 경우 매우 치명적인 결과를 초래할 수 있 는 질환이다. 증상이 다른 질환과 비슷하거나 혼동되어 진단 이 늦어진 경우에는 음식물, 소화효소 및 세균 등에 감염되 어 종격동염, 농흥, 패혈증 및 다발성 장기부전으로 사망할 수 있다. ${ }^{5}$

식도 천공의 원인으로는 자연성, 외상성, 이물질, 그리고 의 인성 식도 천공이 있으며 수명의 연장, 의술의 발달 그리고 의료 기구들의 다양화 등으로 인하여 의인성 식도 천공이 증 가하는 추세이다.

자연성 천공은 구토반응 과정에서의 복강내압 증가, 출산, 무거운 물건을 올릴 때, 둔한 복부외상 등 식도내압의 급상 승에 해부생리학적 협착부위 및 식도 근육의 경련성 부조화 로 발생하는 강압성 구토, 흥통, 피하기종의 3대 증상을 가진 Boerhaave's 증후군이 대부분이다. ${ }^{6}$

관통상이나 둔부외상에 의한 외상성 천공은 대부분 경부 식도에 잘 발생하는데, 총상이나 자상으로 인한 관통성 손 상과 자동차의 증가와 산업의 발달로 인한 둔부 외상이 주요 원인이며 사망률과 이환율은 동반된 손상과 관계가 많다."

반면 이물질이나 부식성 물질에 의한 천공은 흉부 식도에 주로 일어나며, 해부학적 협착부위인 윤상인두, 좌주기관지 와 대동맥궁의 만남부위, 하부식도 괄약근직상부에서 발생한 다. ${ }^{89)}$ 본 연구에서는 지역적인 원인으로 생선 가시나 조개 껍 질류에 의한 이물질에 의해 주로 윤상인두와 좌측 흥곽에 식도 천공이 호발하였다.

최근 내시경 및 식도내 기구조작 등의 사용 증가로 의인성 식도 천공의 빈도가 점차 증가하고 있으며, 과거에는 자연성 또는 외상성이 많았으나, 현재에는 의인성이 주요 원인이다. ${ }^{10,11}$ 본 연구에서는 자연성 22명(31.0\%), 이물질 섭취 18명(25.4\%), 외상성 17명(23.9\%), 의인성 14명(19.7\%) 순으로 국내외에서 연구 발표한 원인과는 다른 결과를 나타내었다.

1992년 Jones와 Ginsberg ${ }^{12)}$ 는 의인성 식도 천공 중 전방 경추 수술, 종격동경, 위장 근위부 미주신경 차단술 등과 같 은 수술에 의한 식도 천공이 전체 식도 천공의 약 $8 \%$ 정도라 고 보고하였고, 식도경, 식도 풍선 확장술, 식도 정맥류의 경 화 치료, 기도 삽관의 식도 내 삽입 등과 같은 기구 조작에 의한 식도 천공이 약 $43 \%$ 를 차지한다고 하였다. 식도경으로 인한 발생 빈도는 경성 식도경 검사 시 $0.11 \%$, 연성 식도경 검사 시 $0.018 \sim 0.03 \%$, 그리고 치료 목적의 식도내시경 시에 는 매우 높아 1 10\%로 보고되고 있다. ${ }^{13)}$ 본 연구에서는 식도
근종 적출술, 식도경 및 내시경 및 내시경 검사, 식도 부지, 식도 풍선 확장술, 조직 생검 등에 의해 주로 좌측 흥곽에 식 도 천공이 호발하였다. 본 연구에서는 50 대와 60 대에서 Boerhaave's 증후군이 호발하였고 이로 인한 의인성 식도 천 공의 발생 빈도도 증가하는 것으로 사료된다.

식도 천공의 빠른 진단을 위해서는 환자의 병력 매우 중요 하며 자연성 천공의 경우는 과음의 병력과 알코올성 췌장염, 십이지장 궤양, 수술병력, 반복적인 구토와 흥통의 경험 등을 확인하고 동반 기저 식도질환인 궤양, 협착, 게실, 무이완증, 결핵성 식도염, 알코올성 간경화 여부를 물어보는 것이 필요 하다. 이물질인 경우는 이물질 섭취에 대한 구체적인 보고와 의인성인 경우는 수술과 시술의 경험, 외상성인 경우는 외상 의 정도와 위치 등을 파악하여 식도 천공에 대한 조기 인식이 필요하리라 사료된다.

식도 천공의 증상은 천공부 염증의 정도에 따라 달라질 수 있는데 통증, 발열 및 연하곤란이 대부분의 초기 증상이다. 경부식도 천공의 경우 연하 시 통증을 호소하게 되며 경부 알 력음도 나타난다. 흉부식도 천공의 경우 발열, 호흡곤란 및 흥통을 호소하는 경우가 많으며 청색증이나 쇼크도 발생할 수 있다. 그 외 기흥, 종격동 기종, 수흥 등이 발생할 수 있다. 본 연구에서는 흥부나 경부 통증이 가장 많았고, 호흡곤란, 피하기종, 구토 순이었다.

시술 후에 경부, 흉부, 복부의 통증이 생기면 식도 천공을 의심하고 단순흥부촬영에서 종격동 기종, 기흥, 심낭 기종, 늑 막삼출, 횡격막하 공기 음영 등이 관찰되면 식도 천공을 예상 해야 하고 곧 식도 조영술을 시행해야 한다. ${ }^{14)}$ 식도 천공 치 료가 천공 후 24시간 내에 이루어질 경우 사망률이 10 20\% 정도이나 48시간 이후 이루어질 경우 사망률이 약 $60 \%$ 까지 증가될 수 있기 때문에, ${ }^{1-3)}$ 식도 조영술에서 정상 소견이 보여 도 임상적으로 의심이 될 때는 식도경과 전산화단층촬영을 시행하는 것이 좋고 연성 식도 내시경술은 천공을 직접 볼 수 있고 위치를 확인하는 데 가장 정확한 방법이다. 전산화단층 촬영으로 식도주위 종격동의 연조직 부위의 공기, 그리고 늑 막강이나 종격동 부위의 식도와 연결된 농양동공, 혹은 공기 가 찬 식도와 그 부위의 종격동 혹은 종격동 주위에 나타난 공기액체 음영 등을 확인할 수가 있다. 수술적 치료 여부의 결정과 수술 시 경부 또는 흥부로의 접근 방법을 결정하는 데 에도 전산화단층촬영은 필수적이며 추적 관찰 시에도 유용 한 검사이다. ${ }^{15}$

식도 천공이 진단된 후에는 천공의 원인, 부위, 기저 식도 질 환, 식도 천공 후 진단까지의 시간 등을 고려하여 식도 천공 의 치료방법을 결정하여야 한다. 식도 천공의 치료방법은 비 수술적인 보존적 치료, 일차 봉합술, T-tube 배액술, 전환술 
과 배제술, 식도제거술 등이 있다. 1946년 Barrett ${ }^{16)}$ 에 의해 식도 천공에 대해 성공적인 수술적 치료를 처음으로 발표한 후, 1952년 Satinsky와 $\mathrm{Kron}^{17)}$ 이 식도 천공 환자에서 성공적 인 식도 적출술을 시행하였다. 식도 천공 치료는 천공의 원인 과 위치, 식도의 기존 질환 여부, 천공 후 진단까지의 기간, 주 위 조직의 손상 정도, 환자의 연령 및 전신 상태 등을 고려해 야 한다. 식도 천공의 치료 목적은 천공의 오염을 방지하고 염증을 제거하며, 식도의 연속성을 확보하고, 적절한 영양상 태를 회복하고 유지하는 것이다. 따라서 식도 천공의 수술적 치료의 원칙은 감염되고 괴사된 조직을 제거하고, 천공 부위 를 누출이 생기지 않도록 세심하게 봉합하여, 오염되고 감염 된 부위의 배액을 하는 것이다. 회복이 오래 걸리는 경우는 공장루조성술 같은 적절한 영양 공급의 통로를 확보하는 것 이 중요하다. Cameron 등 ${ }^{18)}$ 은 막이 잘 형성된 천공이 종격 동 내에 국한되어 주변조직에 누출되지 않고 경미한 증상에 패혈증 임상증상이 없을 때 금식과 적절한 영양공급, 광범위 항생제 투여, 흥관 거치와 비위관을 통한 적절한 배액으로 치료하는 비수술적 방법을 추천하였다. Michel 등ํㅣ은 응급 수술의 적응증으로 기흥, 종격동 기종, 전신 패혈증 증상, 호 흡부전 등을 들고 있다. $\mathrm{Hagan}^{20)}$ 은 경부 개방술을 할 경우 피부절개를 보통 흥쇄유돌근의 전연과 평행하게 가하면 후 인두 공간이 접근이 용이하게 되며 충분한 배농 및 세척과 함께 천공부위의 일차봉합을 할 수 있다고 하였다. 그러나 천공 후 24시간이 지나면 조직이 약해져 일차봉합이 매우 어 려우며, 천공부위의 접근이나 노출이 용이하지 못하면 일차 봉합 없이 단순한 배액만으로도 충분하다고 하였다. 일차봉 합술은 가장 흔히 사용하는 방법으로 괴사되고 감염된 조직 을 충분히 제거하고 식도의 점막층과 근육층을 봉합하며 근 육층에 충분한 절개를 가하여 정상의 점막을 확인하고 봉합 해야 누출을 방지할 수 있다. 일차봉합술 후 식도 누출을 방 지하기 위해 여러 가지 조직으로 보강을 해 주는데 늑막 각편, 장간막 각편, 늑간 근육 각편, 횡격막 각편 등을 이용할 수 있다. 식도암에 의한 천공이나, 심한 식도전장의 괴사가 있을 시에는 식도 제거술을 시행한다. 경부 식도 천공의 경우 오염 이 심하여 봉합술을 할 수 없을 시는 단순 배액술만 시행하 는 경우도 있고, 흥부 식도 천공의 경우 식도 봉합의 안정성 이 의심되거나 보강 조직이 마땅히 없을 시 T-tube를 식도에 삽입할 수 있다. 오염이 심한 식도 천공의 경우 배제술과 전 환술을 시도해 볼 수 있는데 이 수술은 천공 부위는 봉합을 하고 천공 부위의 하방의 식도는 위식도 역류를 막기 위해 결찰하고 경부 식도는 침의 오염을 막기 위해 식도루술을 시 행한다. 본 연구에서는 보존적 치료 20명(28.2\%), 단순 일차 적 봉합술 7 명(9.9\%), 보강조직을 사용한 일차적 봉합술 32
명(45\%), T-tube 배액술 7명(9.9\%), 배제술과 전환술 3명 (4.2\%), 식도 제거술 2명(2.8\%)에게 시행되었다.

식도 천공 환자의 사망에 대한 위험인자로는 천공의 원인, 부위, 천공에서 치료 시작까지 소요시간, 기저식도질환, 수술 적 치료방법 등이 있다. 항생제와 수액제의 발달, 외과적 수 술기법의 향상 등으로 치료 지연에 따른 합병증은 줄었으나, 24시간 이상의 치료 지연은 아직까지 높은 사망률과 연관되 어 있다.

\section{REFERENCES}

1) Skinner DB, Little AG, DeMeester TR. Management of esophageal perforation. Am J Surg 1980;139(6):760-4.

2) Sarr MG, Pemberton JH, Payne WS. Management of instrumental perforations of the esophagus. J Thorac Cardiovasc Surg 1982;84(2): 211-8.

3) Bladergroen MR, Lowe JE, Postlethwait RW. Diagnosis and recommended management of esophageal perforation and rupture. Ann Thorac Surg 1986;42(3):235-9.

4) Okten I, Cangir AK, Ozdemir N, Kavukçu S, Akay H, Yavuzer S. Management of esophageal perforation. Surg Today 2001;31(1):36-9.

5) Heo G, Yoo YS, Kim SW. Virtual endoscopy of impacted foreign bodies in tracheal and esophageal model. Double glomus tumors originating in the submandibular and parotid regions. Korean $\mathrm{J}$ Otorhinolaryngol-Head Neck Surg 2011;54(5):339-43.

6) Kumar N, Rao BS, Shahab T. Boerhaave's Syndrome. J Assoc Physicians India 2015;63(6):62-3.

7) Weiman DS, Walker WA, Brosnan KM, Pate JW, Fabian TC. Noniatrogenic esophageal trauma. Ann Thorac Surg 1995;59(4): 845-9; discussion 849-50.

8) Yoon DB, Sur JR, Kim H. A clinical study on foreign bodies in the food and air passages. Korean J Otolaryngol 1988;31:657-62.

9) $\mathrm{Kim} \mathrm{SH}$, Lee CW, Cho JS. Clinical analysis of tracheoesophageal foreign bodies. Korean J Otolaryngol 1989;32:558-66.

10) Tullavardhana T. Iatrogenic esophageal perforation. J Med Assoc Thai 2015;98 Suppl 9:S177-83.

11) Barthet M, Gonzalez JM. Treatment of iatrogenic esophageal perforation: do we need another tool? Endosc Int Open 2015;3(6): E552-3.

12) Jones WG 2nd, Ginsberg RJ. Esophageal perforation: a continuing challenge. Ann Thorac Surg 1992;53(3):534-43.

13) Miller RE, Bossart PW, Tiszenkel HI. Surgical management of complications of upper gastrointestinal endoscopy and esophageal dilation including laser therapy. Am Surg 1987;53(11):667-71.

14) Han SY, McElvein RB, Aldrete JS, Tishler JM. Perforation of the esophagus: correlation of site and cause with plain film findings. AJR Am J Roentgenol 1985;145(3):537-40.

15) Liguori C, Gagliardi N, Saturnino PP, Pinto A, Romano L. Multidetector computed tomography of pharyngo-esophageal perforations. Semin Ultrasound CT MR 2016;37(1):10-5.

16) Barrett NR. Spontaneous perforation of the oesophagus; review of the literature and report of three new cases. Thorax 1946;1:48-70.

17) Satinsky VP, Kron SD. One-stage esophagectomy in presence of mediastinitis. AMA Arch Surg 1952;64(1):124-7.

18) Cameron JL, Kieffer RF, Hendrix TR, Mehigan DG, Baker RR. Selective nonoperative management of contained intrathoracic esophageal disruptions. Ann Thorac Surg 1979;27(5):404-8.

19) Michel L, Grillo HC, Malt RA. Operative and nonoperative management of esophageal perforations. Ann Surg 1981;194(1):57-63.

20) Hagan WE. Pharyngoesophageal perforations after blunt trauma to the neck. Otolaryngol Head Neck Surg 1983;91(6):620-6. 